\title{
TECNOLOGIAS DIGITAIS DE INFORMAÇÃO E COMUNICAÇÃO (TDIC) EM EDUCAÇÃO ESCOLAR: UM DIAGNÓSTICO A PARTIR DA FORMAÇÃO INICIAL DE PROFESSORES DE MATEMÁTICA
}

\author{
OLIVEIRA, Raquel Gomes de ${ }^{1}$
}

RESUMO: Este artigo apresenta procedimentos e resultados da primeira fase de uma pesquisa, cujo objetivo geral foi diagnosticar a utilização de Tecnologias Digitais de Informação e Comunicação (TDIC) na formação inicial professores de Matemática no âmbito do Estágio Curricular Supervisionado. Na primeira fase, realizada no ano letivo de 2010, buscou-se saber sobre as concepções iniciais dos futuros professores de Matemática quanto à utilização de TDIC na educação escolar e também saber as consequências das experiências vivenciadas nos Estágios Supervisionados sobre essas concepções. A iniciação à utilização de TDIC pelos estagiários ocorreu na primeira fase da pesquisa através de consulta de tecnologias digitais junto ao Banco Internacional de Objetos Educacionais (BIOE), fazendo uso de objetos educacionais que se encontram no mesmo. Os participantes eram licenciandos do $3^{\circ}$ ano de um curso de Licenciatura em Matemática de uma Universidade Pública e professores de Matemática das escolas estaduais da Educação Básica. Os resultados mostram que existiram obstáculos para que os estagiários utilizassem TDIC na educação escolar. No entanto, os resultados também mostram que a utilização de TDIC pode oportunizar aos futuros professores reflexões e elaborações sobre saberes, procedimentos e atitudes significativas ao fazer docente do professor de Matemática.

Palavras-chave: Tecnologias digitais de informação e comunicação. Formação de professores de matemática. Estágio supervisionado.

SUMMARY: This paper reports procedures and results of the first phase of a study, whose overall goal is to diagnose the use of Digital Technologies for Information and Communication (TDIC) in initial mathematics teachers under the Student Teaching. In the first phase, held in academic year 2010, sought to know about the initial conceptions of future teachers of mathematics in the use of TDIC in school education and also know the consequences of supervised experiences in Stages on these concepts. The initiation of the use of TDIC by trainees occurred in the first phase of the research by consulting to the Banco Internacional de Objetos Educacionais (BIOE), making use of learning objects that exist in the same. Participants were undergraduate students of the 3rd year of the Course of Mathematics at a public university and mathematics teachers of state schools of basic education. The results show that there were obstacles so that future teachers had used the TDIC in school education. However, the results also show that the use of TDIC can create opportunities for future teachers reflections and elaborations on knowledge, attitudes and procedures significant to the teaching of the mathematics teacher

Keywords: Digital technologies for information and communication. Mathematics teacher education. Student teaching.

\section{INTRODUÇÃO}

Atualmente através da implementação de políticas públicas brasileiras para programas de informatização social, muitos brasileiros têm tido a oportunidade de acesso a computadores e, consequentemente à internet. Nesse contexto surgem discussões e posicionamentos sobre o papel da escola no mundo atual e a natureza do saber escolar, especificamente quanto a situações de ensino e aprendizagem. Entre esses posicionamentos está aquele que entende a escola como lugar de contradição existente entre oportunidade de acesso à informação e construção de conhecimento, dado o montante de

\footnotetext{
${ }^{1}$ Doutora em Educação pela Universidade de São Paulo. Professora do Departamento de Educação da FCT-Unesp, responsável pelas disciplinas de Didática e de Estágio Supervisionado no Curso de Licenciatura em Matemática.
} 
informação que as Tecnologias Digitais de Informação e Comunicação (TDIC) oferecem, e saber efetivamente construído pelo aluno, o que necessariamente recai na reflexão sobre a origem, natureza e a realização de saberes docentes, dando sentido à afirmação de Maltempi (2008):

O uso do computador e da internet já estão mais difundidos, embora seja importante ressaltar que não defendemos qualquer tipo de uso da tecnologia na educação; somos contrários ao uso que visa exclusivamente ratificar e potencializar o que o professor faz há anos dentro de uma abordagem que evidencia a transmissão de informações de forma mecânica, que geralmente toma o aluno como um "saco vazio" a ser preenchido de saberes pelo professor, e que visa, conforme D'Ambrósio (2005, p.95), "a aquisição de competências que são, em grande parte irrelevantes, obsoletas e desinteressantes na nossa sociedade". (MALTEMPI, 2008, p. 154-155).

Uma hipótese para a defasagem, que resulta dessa contradição, pode ser encontrada na pouca existência de saberes docentes referentes a saberes tecnológicos, especificamente quanto à utilização de Tecnologias Digitais de Informação e Comunicação em situações regulares de aulas de Matemática, por exemplo. Logo, é possível perguntar: o que dever saber um professor sobre Tecnologias de Informação e Comunicação para que estas sejam utilizadas em suas práticas de ensino?

Para a International Society for Technology in Education (ISTE), a competência de um professor para desenvolver, colocar em prática e avaliar experiências com TDIC que levem à efetiva melhoria da aprendizagem do aluno, além de engajamento do aluno no seu próprio processo de aprendizagem, requer a existência de saberes específicos. Em 2008, a ISTE estabeleceu que entre esses saberes devem ser considerados os saberes tecnológicos, que incluem a utilização de tecnologias de informação e comunicação e que levam aprendizes (e aqui também se encontram os professores) a: desenvolver conhecimentos; desenvolver habilidades e disposições pessoais (atitudes) quanto a estratégias de aprendizagem, formulando perguntas significativas sobre um tema, podendo alcançar e selecionar fontes de adequada informação que respondam a essas perguntas e adquirir habilidades que lhe permitam aprender de modo autônomo e colaborativo por toda a vida.

No atual contexto brasileiro de oportunidades de acesso às TDIC, as capacidades e conhecimentos acima concorrem para uma mudança de enfoque educacional. Nessa mudança, a informação necessita do saber aprender a encontrá-la e sua utilização pode ser entendida como parte de fontes de competências específicas, a partir de uma área de conhecimento, a Matemática, por exemplo, e parte de competências gerais que surgem a partir da necessidade de viver em sociedade.

Este texto é sobre uma pesquisa, ainda em andamento, que procura diagnosticar, em termos de dificuldades e conquistas, as primeiras utilizações de TDIC, nos Estágios Supervisionados, por licenciandos de um curso de Licenciatura em Matemática.

Pesquisa que toma como premissa que o século XXI é o século da informação cuja natureza não é somente de recordação, de memorização, mas sim de referência para a construção de conhecimentos, inclusive de conhecimentos docentes nos quais as TIC podem ser apontadas como instrumentos eficazes.

\section{Objetivos da pesquisa}

O objetivo geral desta pesquisa foi diagnosticar a utilização de Tecnologias Digitais de Informação e Comunicação (TDIC) na formação inicial professores de Matemática no âmbito do Estágio Curricular Supervisionado. Para o alcance do objetivo geral, com os seguintes objetivos específicos:

- Saber sobre concepções iniciais dos futuros professores de Matemática quanto à utilização de TDIC na Educação Escolar, antes de fazerem uso destas nos Estágios Supervisionados; 
- Oportunizar aos atuais professores de Matemática da Educação Básica o desenvolvimento e a ampliação de capacidades de utilização de TIC em suas práticas docentes através do conhecimento de objetos educacionais e do Banco Internacional de Objetos Educacionais (BIOE);

- Saber sobre consequências da utilização de TDIC nos Estágios Supervisionados sobre as concepções iniciais dos futuros professores quanto a essa utilização;

- Propiciar ao futuro professor de Matemática oportunidades de realizar e compartilhar o planejamento, o desenvolvimento e a análise de experiências docentes quanto ao uso de TIC com colegas do curso, com atuais professores de Matemática da Educação Básica e com o professor supervisor de Estágio;

- $\quad$ Propor para futuros e para atuais professores de Matemática reflexões sobre a utilização de TDIC em termos de atitudes investigativas, que permitam vivenciar metodologias de ensino que atentem para concepção ativa de aprendizagem, de resolução de problemas, bem como de trabalho individual e em grupo contribuindo para a construção de relações novas e pertinentes tanto para si mesmos, como para a comunidade escolar.

\section{Metodologia}

Esta pesquisa foi iniciada no ano letivo de 2010. O fato de poder ter três anos de duração permitiu que fosse realizada com os mesmos participantes universitários e, em alguns casos, nas mesmas escolas da Educação Básica.

a) Participantes: licenciandos do curso de Licenciatura em Matemática da Faculdade de Ciências e Tecnologia (FCT)- Unesp, matriculados nas disciplinas Estágio Curricular Supervisionado I (ano letivo de 2010) e Estágio Curricular Supervisionado II (ano letivo de 2011), estudantes do ensino fundamental e do ensino médio de escolas estaduais e professores de Matemáticas destes estudantes;

b) Procedimentos metodológicos: A metodologia utilizada na primeira fase pesquisa mesclou dados quantitativos e qualitativos, referendando-se em muitos momentos em ações que caracterizam uma pesquisa-ação (Fazenda, 1991; Elliott, 2000; Barbier, 2002; Tripp, 2006) e também em uma pesquisa descritiva.

Inicialmente fez-se com que os futuros professores de Matemática (licenciandos) trabalhassem conjuntamente com atuais professores de Matemática das escolas utilizando Tecnologias Digitais de Informação e Comunicação (TDIC). Nesse sentido, as horas de Estágio Supervisionado foram entendidas pelos participantes como tempo comum para a utilização de TIC nas aulas de Matemática junto às escolas.

Logo, foram desenvolvidos procedimentos metodológicos a fim de que os participantes elaborassem projetos de ensino que contemplassem o planejamento de situações didáticas para as aulas de Matemática, destacando a utilização de objetos educacionais (OEs) oriundos do Banco Internacional de Objetos Educacionais (BIOE). Para Tarouco et al (2003) um objeto educacional (OE) pode ser entendido como:

Qualquer recurso, suplementar ao processo de aprendizagem, que pode ser reusado para apoiar a aprendizagem. O termo objeto educacional (learning objects) geralmente aplicase a materiais educacionais projetados e construídos em pequenos conjuntos com vistas a maximizar as situações de aprendizagem onde o recurso pode ser reutilizado. A idéia básica é a de que os objetos sejam como blocos com os quais será construído o contexto de aprendizagem. (TAROUCO et al., 2003).

Entre os entendimentos da necessidade de se trabalhar com projeto, existe o que encontra respaldo na seguinte explicação:

A função do projeto é favorecer a criação de estratégias de organização dos conhecimentos escolares em relação a: 1) o tratamento da informação e 2) a relação entre 
os diferentes conteúdos em torno de problemas ou hipóteses que facilitem aos alunos a construção de seus conhecimentos, a transformação da informação procedente dos diferentes saberes disciplinares em conhecimento próprio (HERNANDEZ; VENTURA, 1998, p. 61).

A fim de colaborar com os licenciandos na elaboração de seus projetos de ensino, houve um trabalho sistemático durante as aulas na universidade, dando exemplos de projetos de ensino e discutindo um a um elementos que comumente os compõem, tais como: justificativa, objetivo, metodologia, referências bibliográficas, entre outros.

Acatando ao que se entende por parceria, desde o primeiro momento da pesquisa, os futuros professores foram orientandos nas aulas na universidade a não chegarem às escolas com projetos prontos. Caso contrário, descaracterizaria a parceria escola-universidade e consequentemente a importância e o respeito pelos saberes docentes dos professores que estão nas escolas, juntamente com as agendas escolares e seus currículos, como aponta Oliveira (2006).

Os projetos elaborados conjuntamente por futuros professores e professores das escolas foram orientados pela professora universitária responsável pela disciplina Estágio Curricular Supervisionado I (ano letivo de 2010), tendo em sua maioria continuidade na disciplina Estágio Curricular Supervisionado II (ano letivo de 2011).

Os instrumentos para levantamento de dados da pesquisa foram 2 questionários e o relatório de Estágio entregue pelos futuros professores. Os questionários foram aplicados respectivamente antes e depois da realização dos Estágios Supervisionados. As questões eram as mesmas, mas tiveram a ordem de apresentação alterada no questionário 2. O que justifica apenas a apresentação do questionário 2 no anexo deste artigo.

Algumas aulas na universidade ocorreram no laboratório de informática porque o objetivo dessas aulas era apresentar aos licenciandos um repositório virtual de objetos educacionais, neste caso, o Banco Internacional de Objetos Educacionais (BIOE). O BIOE é parte de um projeto do Ministério da Educação do Brasil (MEC) denominado Portal do Professor. Neste projeto do MEC, a FCT/UNESP participou com uma equipe composta por alunos dos cursos de Matemática, Física Engenharia Ambiental, Química, Estatística e Tradutores para a língua Inglesa e língua Espanhola.

\section{Resultados e análises da pesquisa}

Através do questionário foi possível à pesquisadora saber que dos 43 licenciandos participantes da pesquisa, no ano letivo de 2010, 38 licenciandos (88.4\%) afirmaram que até aquele momento do curso de licenciatura (praticamente $3^{\circ}$ ano do curso) não tinham tido oportunidade de desenvolver um projeto tendo, portanto oportunidade de conhecer elementos que sistematicamente devem estar presentes em um.

Os itens das questões dos questionários 1 e 2 foram formulados com o objetivo de considerar 4 categorias de informação que permitiram chegar ao objetivo da primeira fase da pesquisa:

a) Conceito e utilização de TDIC no processo de ensino e aprendizagem de Matemática (questão 1, do questionário 2);

b) Saberes docentes e saber docente para o ensino de Matemática utilizando TDIC (questão 2, do questionário 2);

c) Conceito de Estágio Curricular Supervisionado em parceria com a escola (questão 3, do questionário 2);

d) Dificuldades para utilizar TDIC na Educação escolar (questão 4, do questionário 2); 
Para a categoria 1 (Conceito e utilização de TDIC no processo de ensino e aprendizagem de Matemática), a alternativa mais marcada antes e depois do desenvolvimento dos Estágios Supervisionados e suas respectivas frequências foram:

- Aprende Matemática de acordo com o planejamento do professor e o papel exercido pelo professor na aula, mesmo que utilize a sala de informática da escola: Antes: 60 \% Depois: $70 \%$.

É provável que as dificuldades encontradas pelos licenciandos para desenvolverem seus projetos juntamente com a necessidade de adequá-los, de reelaborá-los contribuíram para que ideias em relação ao conceito e utilização de TDIC no processo de ensino-aprendizagem da Matemática estivessem mais ainda ligadas à importância do papel do professor, de seus saberes neste processo.

Pode-se também inferir que essa afirmação quanto ao papel do professor tem a ver com a capacidade do mesmo para regular suas ações pedagógicas frente ao contexto encontrado, o que contribui para as defesas dos pressupostos da Cognição Situada (Lave e Wenger, 1991) e também para o objetivo de se evitar nas situações de Estágio Supervisionado o planejamento de ações sem correspondência com o dia a dia do contexto escolar.

Para a categoria 2 (Saberes docentes e saber docente para o ensino de Matemática utilizando TDIC), havia 10 afirmações nos questionários e o respondente deveria marcar até 5 destas. As 5 afirmações mais marcadas e suas comparações foram:

- ter o domínio do conteúdo que irá ensinar: Antes: $79 \%$ Depois: $93 \%$

- ter referências de como o aluno aprende Matemática: Antes: 65 \% Depois: $79 \%$

- saber o que significa TDIC e sua utilização no ensino-aprendizagem de Matemática: Antes: $60 \%$ Depois: $60 \%$

- vontade de utilizar a sala de informática da escola: antes: $30 \%$ depois: $14 \%$

- ter tempo para preparar atividades que utilizem TDIC nas aulas de Matemática: Antes: $67 \%$ Depois: $74 \%$

As alternativas sobre domínio de conteúdo matemático que irá ensinar, sobre referências de como o aluno aprende Matemática e sobre disponibilidade de tempo do professor tiveram suas frequências aumentadas após a realização dos Estágios Supervisionados. Nesse sentido, e possível afirmar que ideias errôneas nas quais apenas a utilização de TDIC é suficiente para o processo pedagógico, em detrimento de saberes docentes necessários e insubstituíveis, entre eles, saber o conteúdo a ser ensinado, saber a pedagogia deste conteúdo, saber como um aluno aprende, perdem forças frente a dados da realidade. Assim, a utilização de TDIC nos Estágios deve ter levado os licenciandos a refletirem sobre implicações necessárias ao utilizá-las com os alunos em situações de ensino e aprendizagem de Matemática sala de aula.

É possível afirmar ainda que o desenvolvimento dos Estágios Supervisionados buscando utilizar TDICs também implicou que o conceito, de senso comum, mas muito propagado no qual a utilização de TDIC em situações escolares apenas dependa "da vontade do professor para utilizar a sala de informática da escola", tivesse a frequência de opções no questionário 2 bastante reduzida. Este fato permite pensar novamente na necessidade de oferecimento de dados de realidade, quanto à utilização de TDIC nas escolas para os cursos de formação inicial de professores. O que certamente foi permitido pela realização dos Estágios proposta nesta pesquisa.

Sobre o tempo necessário para preparar atividades que utilizem TDIC na sala de aula, surge a seguinte questão: se os licenciandos não tivessem que desenvolver projetos de Estágio com uso de TDIC, o aumento de frequência para essa alternativa seria o mesmo? Ou o aumento de frequência a essa alternativa reflete a importância de se desenvolver um Estágio que respeite a agenda escolar e no qual as situações do dia a dia da escola façam parte da vivência de Estágio do futuro professor, pois assim, desde

Nucleus, v.9, n.2, out.2012 
a formação inicial a ideia de ter tempo no trabalho docente para a utilização de TDIC já se estabeleça? Pelo que se tem de experiências quanto ao uso de TDIC em Educação, precisamente nos processos de ensino-aprendizagem de conteúdos escolares, o tempo que o professor da escola deveria ter para preparar suas aulas e o espaço pedagógico no qual estas deverão acontecer tem sido praticamente mínimo e em muitos casos inexistente.

A experiência vivenciada nos Estágios que buscaram utilizar TDIC em Educação deve ter contribuído para esse reafirmar dos licenciandos sobre o tempo necessário para o professor enquanto uma das condições docentes necessárias ao professor de Matemática.

Já para a categoria 3 (Conceito de Estágio Curricular Supervisionado em parceria com a escola), os resultados mostraram que a ideia de parceria escola-universidade que seja independente das condições e dos incentivos encontrados na escola, sofreu uma significativa redução de frequência. Essa redução pode ser considerada, como sendo, reflexo do que os licenciandos encontraram nas escolas para a realização dos Estágios. Pela análise dos relatórios de Estágio, muito do que foi considerado pelos licenciandos enquanto oportunidades e condições para o desenvolvimento dos Estágios dependeu de ações particulares, isto é, da boa vontade de professores, diretores, coordenadores pedagógicos e alunos das escolas.

Considerar uma parceria como fator positivo para a utilização de TDIC no ensino e aprendizagem de Matemática, existindo condições e incentivos encontrados na escola, continuou sendo o item mais frequente para os licenciandos permitindo inferir que para os futuros professores de Matemática deste estudo, incentivos e condições devem ser encontrados nas escolas, de maneira institucionalizada e não particularizada contando com voluntariedade dos profissionais e alunos que lá estão. Oliveira (2006) afirma que era prática muito comum, e ainda é, que os estagiários chegassem às escolas para aplicar atividades desenvolvidas em completo isolamento da sala de aula na qual estavam estagiando, descaracterizando uma autêntica parceria no sentido de Clark (1988).

Propostas de Estágio sob parceria escola-universidade têm mostrado que tomar parte do ambiente escolar e aos poucos ir desenvolvendo saberes específicos da docência, em uma referência ao conceito de Participação Periférica Legítima (Lave e Wenger, 1991), é um caminho bastante útil para um tempo de Estágio proveitoso à formação inicial e também à formação continuada de professores.

No entanto, ainda faltam políticas públicas de institucionalização para parcerias escolauniversidade.

As principais dificuldades para utilizar TDIC na educação escolar (categoria 4), de acordo com os dados desta pesquisa foram:

- Impossibilidade para usar a sala de informática (SAI) ou laboratório de informática porque estava em reforma sem previsão de término para o ano letivo de 2010;

- Utilização de materiais escolares de baixa qualidade, por exemplo, caixas de som com problemas; aquecimento do equipamento de projeção;

- Desinteresse por parte da equipe pedagógica da escola (diretor, vice-diretor, coordenador pedagógico) para que fossem utilizados computadores pelos estagiários e alunos;

- Desinteresse por parte do professor supervisor de Estágio na escola para utilizar a sala de informática;

- Ausência de sala de informática na escola.

Essas dificuldades podem ser consideradas não só obstáculos para o trabalho com a TDIC em educação escolar das pessoas mais próximas às escolas. Mas, sobretudo como impedimentos para um efetivo papel da escola em nossa sociedade que órgãos governamentais buscam garantir. 


\section{CONCLUSÃO}

O trabalho com projetos prima pelo estabelecimento de procedimentos nos quais a elaboração, o desenvolvimento e a ampliação de saberes possuem uma lógica distinta da ordenação linear dos mesmos. O trabalho por projetos se orienta por perspectivas nas quais o conhecimento é globalizado, contextualizado e, portanto, relacional, o que difere da lógica da ordenação rígida de saberes, do estabelecimento de disciplinas pré-estabelecidas e também da ideia de que aprendizes possuem comportamentos homogeneizados e homogeneizáveis.

Então, mesmo que não seja propósito nesta pesquisa desenvolver as horas de Estágio conforme os pressupostos e consequências da Pedagogia do Projeto, é possível afirmar que os objetivos da mesma, na primeira fase, puderam ser alcançados também pelo trabalho com projetos porque têm a ver com "[...] a transformação da informação procedente dos diferentes saberes disciplinares em conhecimento próprio" (HERNANDEZ; VENTURA, 1998), nesse caso em saberes docentes de futuros professores de Matemática.

A análise dos relatórios de Estágio entregues pelos licenciandos para a professora responsável pela disciplina na faculdade no final do ano letivo de 2010 mostra que, com exceção de um estagiário, todos os Estágios desenvolvidos tiveram como base o projeto de Estágio que foi elaborado junto à disciplina e, portanto supervisionado pela professora responsável pela mesma. Por terem seguido o projeto inicial de Estágio, nos relatórios encontram-se tópicos específicos, tais como: justificativa, introdução, objetivos, metodologia, conclusão e referências bibliográficas.

Mesmo com as dificuldades relatadas pelos estagiários para o desenvolvimento dos Estágios Supervisionados é possível afirmar o encontro de positivos resultados tanto para eles como para os atuais professores de Matemática. Entre esses resultados encontram-se:

- Superação da sequência observação-participação-regência para o desenvolvimento do Estágio Curricular Supervisionado;

- Iniciação dos licenciandos à pesquisa, a qual pressupõe o desenvolvimento de habilidades de observar e identificar sistematicamente problemas;

- Desenvolvimento de atitudes metacognitivas dos licenciandos quando pensam sobre seu pensamento, especificamente quanto a condições de utilização de TDIC na escola;

- Desenvolvimento da capacidade de buscar informação, dando sentido tanto ao encontrado como ao caminho percorrido, buscando refletir, escrever sobre o encontrado e o refletido, questionando o que encontrou, fazendo uso do que tem e do que encontrou, propondo mudanças;

- Desenvolvimento de atitudes de trocas e de aprendizagens com os professores que estão na escola já há algum tempo.

- Realização do planejamento, do desenvolvimento e da análise de experiências docentes quanto ao uso de TDIC com colegas do curso, com atuais professores de Matemática da Educação Básica e com o professor supervisor de Estágio na faculdade, em termos do enfoque Ciências Tecnologias e Sociedade (CTS);

- Divulgação e conhecimento de objetos educacionais e do Banco Internacional de Objetos Educacionais (BIOE) junto aos atuais professores de Matemática da Educação Básica;

- Utilização do Estágio Curricular Supervisionado enquanto tempo comum de trabalho para que se efetive uma das possíveis parcerias escola-universidade. 
O objetivo geral desta pesquisa foi diagnosticar a utilização de Tecnologias Digitais de Informação e Comunicação (TDIC) na formação inicial professores de Matemática no âmbito do Estágio Curricular Supervisionado. Em sua primeira fase, buscou-se saber sobre as concepções iniciais dos futuros professores de Matemática quanto à utilização de TDIC na educação escolar e também saber as consequências das experiências vivenciadas nos Estágios sobre essas concepções.

Em um dos instrumentos de levantamento de dados (questionário 2) foi colocada uma questão cuja maior frequência de resposta daria para a pesquisadora uma precisa orientação quanto a continuar ou não pesquisando o tempo de desenvolvimento dos Estágios enquanto espaço comum para formação inicial e contínua de professores de Matemática quanto ao uso de TDIC em Educação Escolar. Isto porque se os licenciandos optassem por buscar outro tema para desenvolverem seus projetos na disciplina Estágio Curricular Supervisionado II (alternativa (b) da questão 5), porque isto foi uma possibilidade levantada na questão, continuar utilizando TDIC, frente à expressa falta de disponibilidade dos futuros professores para este tema, seria pedagogicamente inviável. Ressalta-se que esta pesquisa ocorre de modo simultâneo ao desenvolvimento das disciplinas Estágio Curricular Supervisionado I e Estágio Curricular Supervisionado II em um curso de Licenciatura em Matemática.

Todavia, $75 \%$ dos licenciandos do período diurno e $89 \%$ dos licenciandos do período noturno afirmaram que apesar das dificuldades encontradas na disciplina Estágio Curricular Supervisionado I, continuaria investindo na oportunidade para desenvolver um projeto utilizando TDIC, na disciplina Estágio Curricular Supervisionado II, pensando nas experiências que poderia adquirir ao aplicar este projeto na escola.

$\mathrm{O}$ fato de estar desenvolvendo uma pesquisa-ação não só permitiu à pesquisadora o levantamento desse dado, como também permitiu que a partir da vontade dos participantes da pesquisa, o tema TDIC em Educação continuasse no desenvolvimento dos Estágios Supervisionados no ano letivo de 2011.

A segunda fase da pesquisa ocorreu no ano letivo de 2011 e seus dados estão em fase de tabulação e análise.

\section{REFERÊNCIAS}

BARBIER, R. A Pesquisa-Ação. Brasília: Plano, 2002.

CLARK, R. School-University Relationships: An Interpretative Review. In: SIROTNIK, K.; GOODLAD, J. (Eds). School-University Partnerships in Action: concepts, cases and concerns. New York: Teachers College Press, 1988.

ELLIOTT, J. What is Action-Research in Schools? In: ELLIOTT, John. La investigación-acción en educación. Madrid: Morata, 2000.

FAZENDA, I. (Org). Metodologia da pesquisa educacional. São Paulo: Cortez, 1991.

HERNANDEZ, F. Cultura visual, mudança educativa e projeto de trabalho. Porto Alegre: Artmed, 2000.

ISTE. International Society for Technology in Education, 2008. Disponível em http://www.iste.org/docs/pdfs/nets-t-standards.pdf?sfvrsn=2. Acesso em 10 jun. 2009.

LAVE, Jean; WENGER, Ettienne. Situated Learning: legitimate peripheral participation. Cambridge: University Press, 1991. 
LÜDKE, M. Pesquisa em Educação: abordagens qualitativas. São Paulo: EPU, 1986.

MALTEMPI, M. V. Prática pedagógica e as tecnologias de informação e comunicação (TIC). In: PINHO, S. Z. (Coord.). Oficinas de Estudos Pedagógicos: reflexões sobre a prática do ensino superior. São Paulo: Cultura Acadêmica: Universidade Estadual Paulista, Pró-Reitoria de Graduação, 2008.

OLIVEIRA, R. G. Estágio Supervisionado Participativo na Licenciatura em Matemática, uma Parceria Escola-Universidade: respostas e questões. São Paulo: s.n., 2006. Tese (Doutorado) - Faculdade de Educação da Universidade de São Paulo.

TAROUCO, L.et al. Reusabilidade de objetos educacionais. Revista Novas Tecnologias na Educação. Porto Alegre, p. 1-11, 2003.

TRIPP, D. Pesquisa-Ação: uma introdução metodológica. In: Educação \& Pesquisa, v. 31, n. 3, p. 443466, set/dez/ 2005. Disponível em http://www.scielo.br/pdf/ep/v31n3/a09v31n3.pdf. Acesso em: maio 2006. 


\section{ANEXO- QUESTÕES QUE COMPUSERAM O QUESTIONÁRIO 2} Questionário 2- ECS I- dezembro de 2010

1) De acordo com o que vivenciou no seu Estágio Supervisionado I, com o uso de TICs no processo de ensino-aprendizagem de Matemática, para você, o aluno: (marque apenas uma alternativa)

a) ( ) aprende mais Matemática, independentemente do papel exercido pelo professor, porque o aluno gosta de mexer no computador;

b) ( ) nem sempre aprende Matemática porque utiliza o computador com outras intenções;

c) ( ) aprende Matemática de acordo com o planejamento do professor para o uso de TICs e o papel exercido pelo professor na aula, desde de que utilize a sala de informática da escola;

d) ( ) aprende Matemática de acordo com o planejamento do professor para o uso de TICs e o papel exercido pelo professor na aula, mesmo que não utilize a sala de informática da escola;

2) Sua experiência com o uso de TICs em Educação, durante o tempo que cursou a disciplina Estágio Curricular Supervisionado I permite afirmar que o professor de Matemática deve: (marque até cinco alternativas)

a) ( ) ter o domínio do conteúdo que irá ensinar;

b) ( ) ter referências de como o aluno aprende Matemática;

c) ( ) ter competência quanto a TIC a ser utilizada;

d) ( ) ter condições de integrar o uso de TIC a materiais como o livro didático e o caderno de atividades proposto pela SEE;

e) ( ) um conjunto de saberes próprios da profissão docente;

f) ( ) vontade de utilizar a sala de informática da escola;

g) ( ) ter tempo para preparar atividades que utilizem TIC nas aulas de Matemática;

h) ( ) ter participado de cursos de formação continuada na área de TIC;

i) ( ) ter formação específica em Computação;

j) ( ) saber o que significa TIC e sua utilização no ensino-aprendizagem de Matemática

3) Para você, desenvolver o Estágio Curricular Supervisionado em parceria com o professor de Matemática da escola: (marque apenas uma alternativa)

a) ( ) poderá influenciar positivamente quanto à utilização de TIC, no ensino-aprendizagem de Matemática pelo trabalho conjunto realizado entre estagiário e professor, que independe das condições e incentivos encontrados na escola;

b) ( ) poderá ser indiferente para a utilização de TIC no ensino-aprendizagem de Matemática porque a escola oferece condições e incentivos para essa utilização que não dependem dessa parceria;

c) ( ) poderá ser um momento de desenvolvimento de competências no uso de TIC para os dois, devendo a equipe pedagógica e a professora da universidade não participarem desta parceria;

d) ( ) poderá influenciar positivamente quanto à utilização de TIC no ensino-aprendizagem de Matemática e desenvolvimento de competências no uso de TIC, desde de que haja condições e incentivos encontrados na escola;

4) Quais foram as dificuldades encontradas pro você para desenvolver seu projeto de Estágio na disciplina ECS I? (marque quantas alternativas quiser) 
a) ( ) ausência de divulgação de TIC aplicada em Educação;

b) ( ) insuficiente formação inicial de professores quanto à competência para uso de TIC em Educação

c) ( ) conceituação errônea sobre o uso de TIC em Educação;

d) ( ) precária organização do trabalho escolar para o uso de TIC em Educação;

e) ( ) insuficiente formação inicial de professores quanto à competência para uso de TIC em Educação

5) Se na disciplina Estágio Curricular Supervisionado II fosse optativo o uso de TICs no projeto de Estágio, você: (marque apenas uma alternativa)

a) ( ) investiria na oportunidade para desenvolver um projeto utilizando TICs pensando nas experiências que poderia adquirir ao aplicar este projeto na escola, apesar das dificuldades encontradas na disciplina ECS I;

b) ( ) buscaria outro tema e forma de trabalhá-lo em seu projeto para a disciplina ECS II; 
